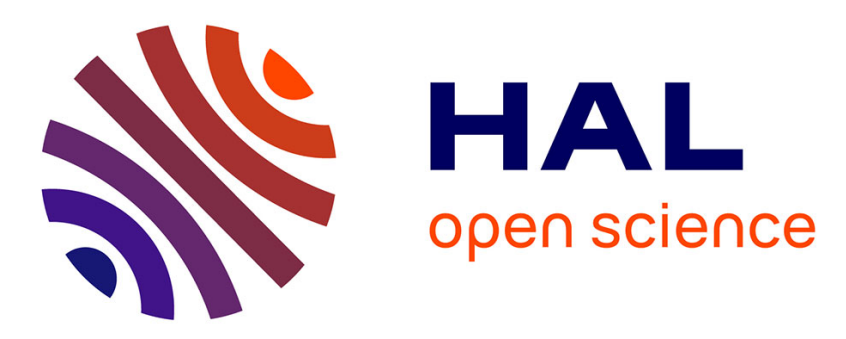

\title{
Velocity and depth distributions in stream reaches: testing European models in Ecuador
}

Virginie Grandgirard, P. Legoulven, R. Calvez, Nicolas Lamouroux

\section{To cite this version:}

Virginie Grandgirard, P. Legoulven, R. Calvez, Nicolas Lamouroux. Velocity and depth distributions in stream reaches: testing European models in Ecuador. Journal of Hydraulic Engineering, 2013, 139 (7), p. 794 - p. 798 . 10.1061/(ASCE)HY.1943-7900.0000726 . hal-00860793

\section{HAL Id: hal-00860793 https://hal.science/hal-00860793}

Submitted on 11 Sep 2013

HAL is a multi-disciplinary open access archive for the deposit and dissemination of scientific research documents, whether they are published or not. The documents may come from teaching and research institutions in France or abroad, or from public or private research centers.
L'archive ouverte pluridisciplinaire HAL, est destinée au dépôt et à la diffusion de documents scientifiques de niveau recherche, publiés ou non, émanant des établissements d'enseignement et de recherche français ou étrangers, des laboratoires publics ou privés. 
1 Velocity and depth distributions in stream reaches: testing European models in Ecuador.

2

3

4

5

6 Virginie Girard ${ }^{1}$, Patrick Le Goulven ${ }^{2}$, Roger Calvez $^{3}$, Nicolas Lamouroux ${ }^{4}$

7

8

9

10

11

12

13

14

15

16

17

18

19

\footnotetext{
${ }^{1}$ Ph.D. Student, IRSTEA, UR MALY, 5 rue de la Doua, CS70077, F-69626 Villeurbanne, France (corresponding author). E-Mail: virginie.girard@irstea.fr

${ }^{2}$ Research director, IRD, UMR GEAU, Apartado 1712 857, Quito, Ecuador.

${ }^{3}$ Research engineer, IRD, UMR GEAU, Apartado 1712 857, Quito, Ecuador.

${ }^{4}$ Research director, IRSTEA, UR MALY, 5 rue de la Doua, CS70077, F-69626 Villeurbanne, France.
} 
Abstract

22 We tested how European statistical hydraulic models developed in France and Germany

23 predicted the frequency distributions of water depth and point-velocity measured in 14

24 reaches in Ecuador during 25 surveys. We first fitted the observed frequency distributions to

25 parametric functions defined in Europe and predicted the parameters from the average characteristics of reaches (e.g. discharge rate, mean depth and width) using European regressions. When explaining the frequency of three classes of velocity and three classes of depth among reach surveys, the fitted and predicted distributions had a low absolute bias $(<$ $3 \%$ ). The residual variance of fits relative to the mean class variance was $<18 \%$. The residual variance of predicted frequencies was 30-61\% for velocity classes and 20-36\% for depth classes. Overall, the European models appeared appropriate for Ecuadorian stream reaches but could be improved. Our study demonstrates the transferability of statistical hydraulic models between widely-separated geographic regions.

36 CE Database subject headings: Rivers and streams; Velocity and depth distributions;

37 Model tests; Stochastic models; Hydraulic models.

38 Authors keywords: Statistical hydraulic model; Frequency distributions; Tropical alpine 39 region 


\section{Introduction}

The knowledge of the distribution of point hydraulic variables (e.g. shear stress, velocity or water depth) in natural stream reaches is of interest for hydraulic engineers (Chiu and Tung 2002), fluvial geomorphologists (Rosenfeld et al. 2011) and stream ecologists (Mérigoux et al. 2009). Deterministic numeric models are frequently used to predict and map hydraulic patterns within reaches, but are still difficult to apply in complex flow conditions (Legleiter et al. 2011). Statistical hydraulic models that predict the frequency distribution of point hydraulic variables have been proposed as a simple alternative. They are based on the observation that point hydraulic variables have comparable frequency distributions in many natural reaches (Lamouroux et al. 1995; Stewardson and McMahon 2002). These frequency distributions can be fitted to parametric probability functions, and the parameters can be predicted from average reach characteristics (e.g. discharge, mean depth, mean width, mean particle size; Lamouroux et al. 1995; Schweizer et al. 2007; Saraeva and Hardy 2009).

Consequently, knowledge of mean depth-discharge and width-discharge relationships in reaches (i.e. at-a-reach hydraulic geometry relationships, Lamouroux 2007) can be used to predict the distributions of point hydraulic variables at various discharge rates using statistical hydraulic models.

The univariate statistical models for at-a-point velocity (time-averaged but not depthaverage along a vertical profile) and water depth initially developed by Lamouroux et al.

61 (1995) and Lamouroux (1998) in small to large French and German reaches have been calibrated in rivers with slopes $<4 \%$ and relative roughness (i.e. average particle size relative to average reach depth) averaging 0.57 (Table 1). Saraeva and Hardy (2009) tested these models in small streams in the lowland part of a temperate watershed (British Columbia in

65 North America) where mean annual flows are less than $3.5 \mathrm{~m}^{3} \cdot \mathrm{s}^{-1}$. They concluded that the 
66 statistical approach was applicable to their rivers, but that the parametric models and their relationships with average reach characteristics had to be adapted. Stewardson and McMahon (2002) and Schweizer et al. (2007) proposed further developments of statistical models, including bivariate models that predict the joint distributions of depth and depth-averaged velocity.

In this study, we test the transferability of the velocity and depth distribution models of Lamouroux et al. (1995) and Lamouroux (1998) (hereafter European models) in 14 Ecuadorian reaches, and propose improved models for tropical Andean streams (> $3500 \mathrm{~m}$ a.s.1.). Ecuadorian tropical highlands streams have morphologic and climatic characteristics that often differ from the European ones (Boulton et al. 2008). They have variable morphologies due to recent volcanic and glacial activities (Jacobsen 2008). Glacial-streams, generally characterized by straight high-gradient channels and torrential flows, contrast with streams in moorland valleys with low gradients, deep and sinuous channels (Jacobsen 2008).

Precipitation averages between 500 and 3000 mm.year ${ }^{-1}$ (Buytaert et al. 2011). Stream hydrology is characterised by diel discharge variations, partly due to snowmelt, but a low seasonal variability due to porous soils (ash deposits) that smooth out base flows (Buytaert et al. 2011).

\section{The existing European models}

87 The univariate European models of Lamouroux et al. (1995) (Eq. (1)) and Lamouroux (1998) (Eq. (2)) concern respectively $f_{u}$ (the distribution of the relative velocity $u / U$; where $u$ is the point velocity and $U$ its reach average, see Notations) and $f_{h}$ (the distribution of the relative 90 depth $h / H$, where $h$ is total depth and $H$ its reach average). 


$$
f_{u}(x=u / U, s)=s \cdot\left\{3.33 \cdot \exp \left(-\frac{x}{0.193}\right)+0.117 \cdot \exp \left[-\left(\frac{x-2.44}{1.73}\right)^{2}\right]\right\}+(1-s) \cdot\left\{0.653 \cdot \exp \left[-\left(\frac{x-1}{0.864}\right)^{2}\right]\right\}
$$

$$
f_{h}(x=h / H, t)=t \cdot \exp (-x)+(1-t) \cdot\left\{0.951 \cdot \exp \left[-\left(\frac{x-1}{0.593}\right)^{2}\right]\right\}
$$

value and one decentred, corresponding to more heterogeneous distributions. The mixing parameters $s$ (Eq. (1)) and $t$ (Eq. (2)) vary between 0 and 1 and were the only parameters

97 fitted to the observed distributions in a reach in the current study. We did not alter the other constants in Eq. (1) and (2), that originate from fits to the average observed distribution in Europe. Lamouroux et al. (1995) proposed three equations of increasing complexity to

100 predict $s$ as a function of average characteristics of reaches (Table 2). Lamouroux (1998)

101 predicted changes in $t$ across discharge rates, i.e. he predicted $t$ at a mean depth $H$ knowing $t_{0}$ at a mean depth $H_{0}$. Both models reflected that the distributions tended to normalize with increasing discharge rates.

\section{Data collection}

108 We sampled 14 reaches (length $~ 20$ wetted width) in seven rivers, at two surveys except for

109 three reaches (one survey only). Reaches had catchment areas between 6 and $105 \mathrm{~km}^{2}$ and

110 altitudes between 3900 and $4500 \mathrm{~m}$ a.s.l. They were situated in three sub-regions:

111 Papallacta's streams are only fed by subsurface runoff from rainwater, whereas Antizana

112 (close to glacier) and Cotopaxi (far from glacier) receive additional glacial inputs.

113 Width:depth ratio varied between 4 and 46 (mean 14), sinuosity varied between 1 and 2.8 
114 (mean 1.7). Reaches were on average faster-flowing, shallower and narrower than European reaches (Table 1). Woody debris were absent but a few emergent boulders were observed.

117 We sampled hydraulic variables on a grid composed of regularly-spaced cross sections along

118 the reach, and regularly-spaced verticals along the cross-sections, whose number depended

119 on the reach heterogeneity. Finally, we sampled an average of 90 verticals [minimum 42, maximum 135] situated along 25 cross-sections [12 - 40] per reach. For each cross-section, we measured the wetted width $w$. At each vertical along the cross section, we measured $h$, a number of point velocities $(u)$ along the vertical, and bed particle size $(d)$. We measured $u$ with a propeller at two $\mathrm{cm}$ and at $0.4 \mathrm{~h}$ above the bed along each vertical. Additional measurements at heights of $0.2 h$ and $0.8 h$ were made when $h>30 \mathrm{~cm}$. Instantaneous velocities were averaged over a $30 \mathrm{~s}$ period, reduced to $15 \mathrm{~s}$ in 8 surveys where discharge rate was variable.

\section{Data processing and analyses}

131 We derived observed $f_{u}$ and $U$ after interpolating $u$ measurements every $\mathrm{cm}$ along verticals.

132 We assigned 0 for the velocity at the bottom, and the velocity measured at the higher point

133 along the vertical for the velocity at the surface. Linear and spline interpolations were tested

134 considering that velocity profiles can differ from the logarithmic theoretical shape in natural reaches (e.g. Wiberg and Smith 1991). Results were comparable and only those associated with linear interpolation are described here. 
139 predicted distributions (where $s$ and $t$, noted $s_{\text {pred }}$ and $t_{\text {pred }}$, are predicted from characteristics

140 of reaches using the unmodified European regressions, Table 2) and improved predictions

141 (where $s$ and $t$, noted $s_{i m p r}$ and $t_{\text {impr }}$, are obtained by new regressions fitted in Ecuador, Table

142 2). For improved predictions (models 4 and 6 in Table 2), the candidate explanatory variables

143 were those already used for velocity in Europe (model 3), to which we added the reach

144 bottom slope ( $i$ ) and the Reynolds number (Re, see Notations) as suggested by Stewardson 145 and McMahon (2002) and Schweizer et al. (2007). Note that our improved depth model did 146 not use to knowledge of $t_{0}$ at one calibration discharge rate, thereby simplifying the European 147 model.

148 We quantified how fits, predictions and improved predictions explained the observed 149 frequencies of three classes of velocity and depth (low, $u / U<1 / 2, h / H<1 / 2$; intermediate, $1 / 2<u / U<2,1 / 2<h / H<2$; and high values, $u / U>2, h / H>2)$.

\section{Results}

The unexplained variance associated with the fits $(U V$, calculated as the ratio between the residual variance and the variance of observed frequencies) was $<18 \%$ for all depth and velocity classes, and the average bias was $<3 \%$ in absolute value (see Fig. 2). Therefore, $U V$ of fits were comparable with their equivalents in Europe $(<19 \%$ in the original publications),

159 i.e. the parametric functions defined in Europe were suitable in Ecuador. Consequently, we 160 did not try to adapt the European parametric functions and focused on the predictability of the mixing parameters. 
164 three unmodified European model predicted some variation of observed frequencies in

165 Ecuador, though $U V$ in Ecuador was sometimes higher than $U V$ obtained in Europe (30-43\%

166 in Lamouroux et al. 1995). Accordingly, $s$ values in Ecuador were predicted by the three

167 European models nearly as well $\left(\mathrm{r}^{2}\right.$ between 0.66 and $0.69, \mathrm{P}<0.001$, Table 2$)$ as in Europe

168 ( $\mathrm{r}^{2}$ between 0.61 and 0.78 in Lamouroux et al. 1995). For depth distributions, the $U V$

169 associated with predictions was satisfactory (20-36\%, Fig. 2), slightly higher than $U V$

170 obtained in Europe (5-35\% in Lamouroux 1998). Accordingly, $t$ values in Ecuador were very

171 well predicted by the European models $\left(\mathrm{r}^{2}=0.85, \mathrm{P}<0.001\right.$, Table 2$)$.

values than those obtained with the European regressions (between 26 and 41\%, see examples for model 2 in Fig. 2). The prediction of $s$ was also improved $\left(r^{2}=0.79\right.$, Table 2).

Concerning depth, our improved model had comparable $U V(19-31 \%)$ as the European

178 discharge rate.

\section{Discussion}

183 Two of our results further demonstrate the generality of statistical hydraulic models, in

184 tropical Andean streams and likely in other geographic regions (e.g. Stewardson and MacMahon 2002). First, the European statistical models performed nearly as well in Ecuador as in Europe, with a low bias and slightly higher residual variance. Second, the European velocity model involving only $\mathrm{Fr}$ performed well in Europe and in Ecuador, supporting that this variable is an important predictor of hydraulic distributions within reaches. This result is 
189 consistent with previous studies made at scale of reaches (Schweizer et al. 2007) or

190 geomorphic units (Rosenfeld et al. 2011). High $F r$ values generate more homogeneous

191 velocity distributions, due to the homogenisation of riffle-pool patterns (Jowett 1993). The

192 relative roughness, identified as a useful predictor in Europe, was not included in our

193 improved models in Ecuador, likely due to the reduced range of particle size in Ecuador

194 (Table 1). Indeed, the effect of relative particle size on hydraulic distributions has been observed in other studies (Schweizer et al. 2007) and $D / H$ influences the shape of velocity profiles (e.g. Hoover and Ackerman 2004; Rhoads et al. 2003).

198 European model, and our improved depth model showed the possibility to predict depth

199 distribution without calibration at one discharge rate. These results indicate the potential of

200 refining the statistical approach in particular geographic contexts. Further improvement of the models could be obtained by including variables describing bank composition (Rhoads et al. 2003), bank stability (Millar and Quick 1993), the relative submergence of bedforms (Wilcox and Wohl 2007) or the variability of bed elevation (Aberle and Smart 2003). Investigating such effects would benefit from additional data collection in contrasting geomorphologic contexts (e.g. streams with very large relative roughness, steep slopes, tropical regimes).

\section{Acknowledgment}

This study was supported by Empresa Publica Metropolitana de Agua Potable y Saneamiento

211 (EPMAPS) of Quito. We thank all the participants who contributed to collect data for the

212 AQUANDES project. We thank Ton Snelder for linguistic advice. 


\section{Notation}

215 The following symbols are used in the paper:

Functions and parameters

$f_{u}=$ distribution of relative velocity $u / U$

$f_{h}=$ distribution of relative depth $h / H$

$s=$ mixing parameter for velocity distributions

$t=$ mixing parameter for depth distributions

Reach characteristics

$Q=$ discharge rate $\left(\mathrm{m}^{3} \cdot \mathrm{s}^{-1}\right)$

$U=$ reach averaged velocity $\left(\mathrm{m} \cdot \mathrm{s}^{-1}\right)$

$H=$ reach averaged depth $(\mathrm{m})$

$D=$ reach averaged particle size $(\mathrm{m})$

$W=$ reach averaged wetted width $(\mathrm{m})$

$\sigma w=$ standard deviation of wetted width among cross-section $(\mathrm{m})$

$F r=$ Froude number defined as $U / \sqrt{ }(g . H)$

$R e=$ Reynolds number $(U . H) / v$. Multiplied by $10^{-6}$ throughout this paper

$i=$ reach slope $(\%)$

Local hydraulic variables

$u=$ point velocity (time-averaged but not depth-averaged) $\left(\mathrm{m} \cdot \mathrm{s}^{-1}\right)$

$h=$ water depth (m)

$d=$ bed particle size $(\mathrm{m})$

$w=$ cross-section wetted width $(\mathrm{m})$

\section{Constants}

$g=$ gravitational acceleration $\left(\mathrm{m} \cdot \mathrm{s}^{-2}\right)$

$v=$ water kinematic viscosity, considered as equal to $10^{-6}\left(\mathrm{~m}^{2} \cdot \mathrm{s}^{-1}\right)$ 


\section{References}

219

220 Aberle, J., and Smart, G. M. (2003). "The influence of roughness structure on flow resistance

221 on steep slopes." J. Hydrau. Res., 41(3), 259-269.

222

223 Boulton, A.J., Boyero, L., Covich, A.P., Dobson, M., Lake, S., and Pearson, R. (2008). “Are

tropical streams ecologically different from temperate streams?" Tropical Stream Ecology,

Academic press. Elsevier Inc., San Diego, pp. 257-284.

226

227

Buytaert, W., Cuesta-Camacho, F., and Tobon, C. (2011). "Potential impacts of climate

change on the environmental services of humid tropical alpine regions." Global Ecol.

229

Biogeogr., 20(1), 19-33.

230

231 Chiu, C.L., and Tung, N.C. (2002). "Maximum velocity and regularities in open-channel

232 flow." J. Hydraul. Eng., 128(4), 390-398.

233

234 Hoover, T.M., and Ackerman, J.D. (2004). "Near-bed hydrodynamic measurements above

235 boulders in shallow torrential streams: Implications for stream biota.” J. Environ. Eng. Sci., $2363(5), 365-378$.

238 Jacobsen, D. (2009). "Classical alpine stream types on the equator: are they different?" Int.

239 Assoc. Theor. Appl. Limnol. Proc., 30(8), 1245-1250.

241 Jowett I., G. (1993). "A Method for Objectively Identifying Pool, Run, and Riffle Habitats

242 from Physical Measurements." N.Z. J. Mar. Freshwat. Res., 27(2), 241-248. 
244 Lamouroux, N. (1998). "Depth probability distributions in stream reaches." J. Hydraul. Eng., 124(2), 224-227.

247 Lamouroux, N. (2007). "Hydraulic geometry of stream reaches and ecological implications."

248 Gravel-bed rivers 6: From process understanding to river restoration, Elsevier Inc.,

249 Amsterdam, pp. 661-675.

250

251 Lamouroux, N., Souchon, Y., and Herouin, E. (1995). "Predicting velocity frequency-

252 distributions in stream reaches." Wat. Resour. Res., 31(9), 2367-2375.

253

254 Legleiter, C.J., Kyriakidis, P.C., McDonald, R.R., and Nelson, J.M. (2011). "Effects of uncertain topographic input data on two-dimensional flow modelling in a gravel-bed river."

Wat. Resour. Res., 47(3), W03518. doi:10.1029/2010WR009618.

Mérigoux, S., Lamouroux, N., Olivier, J.M., and Dolédec, S. (2009). "Invertebrate hydraulic preferences and predicted impacts of changes in discharge in a large river." Freshw. Biol., 54(6), 1343-1356.

262 Millar, R.G., and Quick, M.C. (1993). "Effect of bank stability on geometry of gravel rivers."

263 J. Hydraul. Eng., 119(12), 1343-1363.

265 Rhoads, B.L., Schwartz, J.S., and Porter, S. (2003). "Stream geomorphology, bank

266 vegetation, and three-dimensional habitat hydraulics for fish in Midwestern agricultural

267 streams." Wat. Resour. Res., 39(8), 2.1-13. 
269 Rosenfeld, J.S., Campbell, K., Leung, E.S., Bernhardt, J., and Post, J. (2011). "Habitat effects on depth and velocity frequency distributions: Implications for modeling hydraulic variation and fish habitat suitability in streams." Geomorpholog., 130(3-4), 127-135.

273 Saraeva, K., and Hardy, T.B. (2009). "Prediction of fisheries physical habitat values based on hydraulic geometry and frequency distributions of depth and velocity." J. River Basin Manag., 7(1), 31-41.

276

277 Schweizer, S., Borsuk, M.E., Jowett, I., and Reichert, P. (2007). "Predicting joint frequency

278 distributions of depth and velocity for instream habitat assessment." River Res. Appl., 23(3), 287-302.

280

281 Stewardson, M.J., and McMahon, T.A. (2002). "A stochastic model of hydraulic variations

282 within stream channels." Wat. Resour. Res., 38(1), 8.1-14.

283

284 Wiberg, P.L., and Smith, J.D. (1991). "Velocity distribution and bed roughness in high

285 gradient streams.” Wat. Resour. Res., 27(5), 825-838.

286

287 Wilcox, A.C., and Wohl, E.E. (2007). "Field measurements of three-dimensional hydraulics 288 in a step-pool channel." Geomorpholog., 83(3-4), 215-231. 


\section{LIST of TABLES}

290

291 Table 1. Minimum, mean and maximum values of reach-averaged characteristics for the

292 Ecuador and European data sets considered. Data from Europe were extracted from

293 Lamouroux et al. (1995, velocity model) and Lamouroux (1998, depth model). When the

294 comparison was possible (*) indicates a different mean value in Europe (velocity data set) compared to Ecuador (Wilcoxon rank sum test, $\mathrm{P}<0.05$ ).

296

297

Table 2. European predictions and improved models for velocity and depth distribution in stream reaches (mixing parameters $s$ and $t$ of Eqs. (1) and (2)). Models 1-3 are the European velocity models of Lamouroux et al. (1995). Model 4 allows additional explanatory variables, selected using a stepwise procedure based on Akaike Information Criterion, and shown in the order the entered the regression. Model 5 is the European depth model of Lamouroux (1998).

Model 6 excludes $t_{0}$ and $H_{0}$ from explanatory variables but allows additional explanatory variables, shown in the order they entered the regression. See Notations for variable definitions. The coefficient of determination $r^{2}$ corresponds to the regression between best fits in Ecuador and predicted or improved values. $\mathrm{N}=25$ for all models except model $5(\mathrm{~N}=11)$, which predicts $t$ at one discharge from the knowledge of $t_{0}$ at a lower discharge. All P-values associated with regressions were $<0.001$. Standard errors of coefficients are provided in parentheses. 
Table 1. Minimum, mean and maximum values of reach-averaged characteristics for the Ecuador and European data sets considered. Data from

Europe were extracted from Lamouroux et al. (1995, velocity model) and Lamouroux (1998, depth model). When the comparison was possible

(*) indicates a different mean value in Europe (velocity data set) compared to Ecuador (Wilcoxon rank sum test, $\mathrm{P}<0.05$ ).

\begin{tabular}{|c|c|c|c|c|c|c|c|c|c|}
\hline \multirow[t]{2}{*}{ Reach characteristic } & \multicolumn{4}{|c|}{ Ecuadorian data } & \multicolumn{3}{|c|}{ European velocity model } & \multicolumn{2}{|c|}{ European depth model } \\
\hline & minimum & mean & & maximum & minimum & mean & maximum & minimum & maximum \\
\hline Catchment area $\left(\mathrm{km}^{2}\right)$ & 6.5 & 35.4 & & 104.3 & & & & & \\
\hline Sinuosity (-) & 1.0 & 1.7 & & 2.8 & & & & & \\
\hline$Q\left(\mathrm{~m}^{3} \cdot \mathrm{s}^{-1}\right)$ & 0.060 & 0.450 & * & 1.851 & 0.060 & 2.513 & 20.160 & 0.003 & 1110.000 \\
\hline$W(\mathrm{~m})$ & 1.4 & $3.6=$ & $*$ & 11.5 & 5.1 & 17.2 & 109.4 & 1.0 & 293.0 \\
\hline$U\left(\mathrm{~m} \cdot \mathrm{s}^{-1}\right)$ & 0.14 & 0.41 & $*$ & 0.78 & 0.03 & 0.29 & 0.62 & & \\
\hline$H(\mathrm{~m})$ & 0.17 & 0.27 & $*$ & 0.36 & 0.19 & 0.37 & 0.94 & 0.11 & 3.80 \\
\hline$D(\mathrm{~m})$ & 0.022 & 0.099 & $*$ & 0.159 & 0.020 & 0.192 & 0.520 & & \\
\hline$i(\%)$ & 1.2 & 2.2 & & 3.0 & & & 4.0 & & \\
\hline$F r(-)$ & 0.09 & 0.25 & * & 0.44 & 0.01 & 0.12 & 0.41 & & \\
\hline$D / H(-)$ & 0.08 & 0.40 & & 0.75 & 0.04 & 0.57 & 1.58 & & \\
\hline
\end{tabular}


Table 2. European predictions and improved models for velocity and depth distribution in stream reaches (mixing parameters $s$ and $t$ of Eqs. (1) and (2)). Models 1-3 are the European velocity models of Lamouroux et al. (1995). Model 4 allows additional explanatory variables, selected using a stepwise procedure based on Akaike Information Criterion, and shown in the order the entered the regression. Model 5 is the European depth model of Lamouroux (1998). Model 6 excludes $t_{0}$ and $H_{0}$ from explanatory variables but allows additional explanatory variables, shown in the order they entered the regression. See Notations for variable definitions. The coefficient of determination $r^{2}$ corresponds to the regression between best fits in Ecuador and predicted or improved values. $\mathrm{N}=25$ for all models except model $5(\mathrm{~N}=11)$, which predicts $t$ at one discharge from the knowledge of $t_{0}$ at a lower discharge. All P-values associated with regressions were $<0.001$. Standard errors of coefficients are provided in parentheses.

\begin{tabular}{lll}
\hline Model & Equation & $\mathrm{r}^{2}$ \\
\hline velocity & & 0.69 \\
1 & $s_{\text {pred }}=-0.15-0.252( \pm 0.068) \cdot \ln (F r)$ & 0.66 \\
2 & $s_{\text {pred }}=-0.275-0.237( \pm 0.057) \cdot \ln (F r)+0.274( \pm 0.131) \cdot(D / H)$ & 0.69 \\
3 & $s_{\text {pred }}=-0.346-0.224( \pm 0.055) \cdot \ln (F r)+0.273( \pm 0.124) \cdot(D / H)+0.411( \pm 0.361) \cdot(\sigma w / W)$ & 0.79 \\
4 & $s_{\text {impr }}=-0.426-0.253( \pm 0.044) \cdot \ln (F r)-0.072( \pm 0.029) \cdot i+0.437( \pm 0.261) \cdot(\sigma w / W)$ & 0.85 \\
depth & & 0.82 \\
5 & $t_{\text {pred }}=t_{0}-0.7 \cdot \ln \left(H / H_{0}\right)$ & \\
6 & $t_{\text {impr }}=-0.233-0.593( \pm 0.366) \cdot \operatorname{Re}-0.184 \cdot( \pm 0.087) \cdot \ln F r+1.495( \pm 0.394) \cdot(\sigma w / W)$ & \\
\hline
\end{tabular}




\section{LIST of FIGURES}

Figure 1. Examples of observed (grey bars), fitted (large solid line) and predicted (fine solid line, models 2 and 5 in Table 2) frequency distributions of $u / U$ at two discharges in one reach (a and b) and $h / H$ in another reach (c). Improved distributions were very close to predicted ones and are not shown for readability. All distributions are shown as frequency distributions of 20 regular classes of relative velocity and depth ranging between $u / U=h / H=0$ and $u / U=$ $h / H=5$. Frequencies of velocities and depth falling outside this range were assigned to the relevant extreme class.

Figure 2. Observed frequencies of three velocity classes as a function of fitted frequencies (a), predicted ones (b, model 2 in Table 2), and improved predictions (c, model 4 in Table 2). Similar graphs for depth models (d: fitted frequencies; e: predicted ones, model 5; f: improved ones, model 6). The three classes of velocity and depth frequencies correspond to (•) low values, $(\circ)$ intermediate values and $(\square)$ high values. $U V$ is the unexplained variance. 
Author-produced version of the article published in J. Hydraul. Eng (2013), 139,7, 794-798

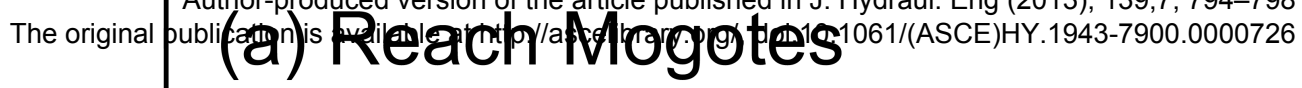
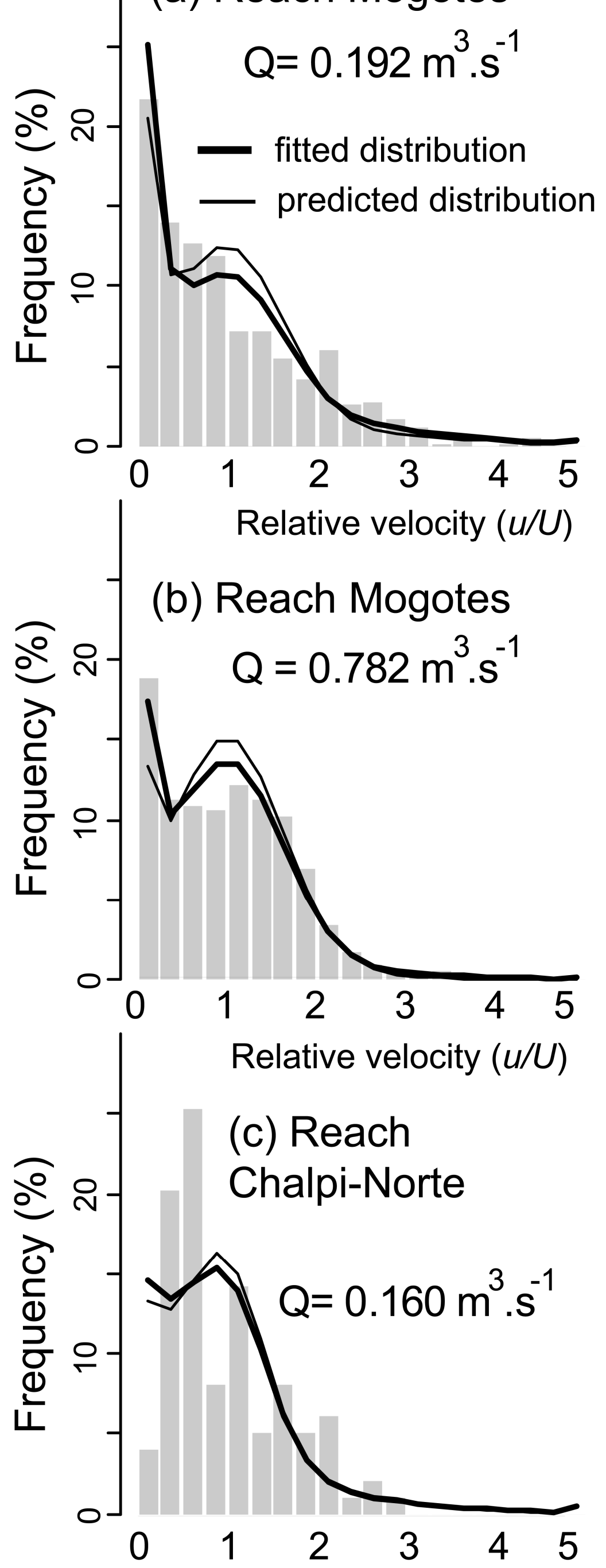

Relative depth $(h / H)$ 


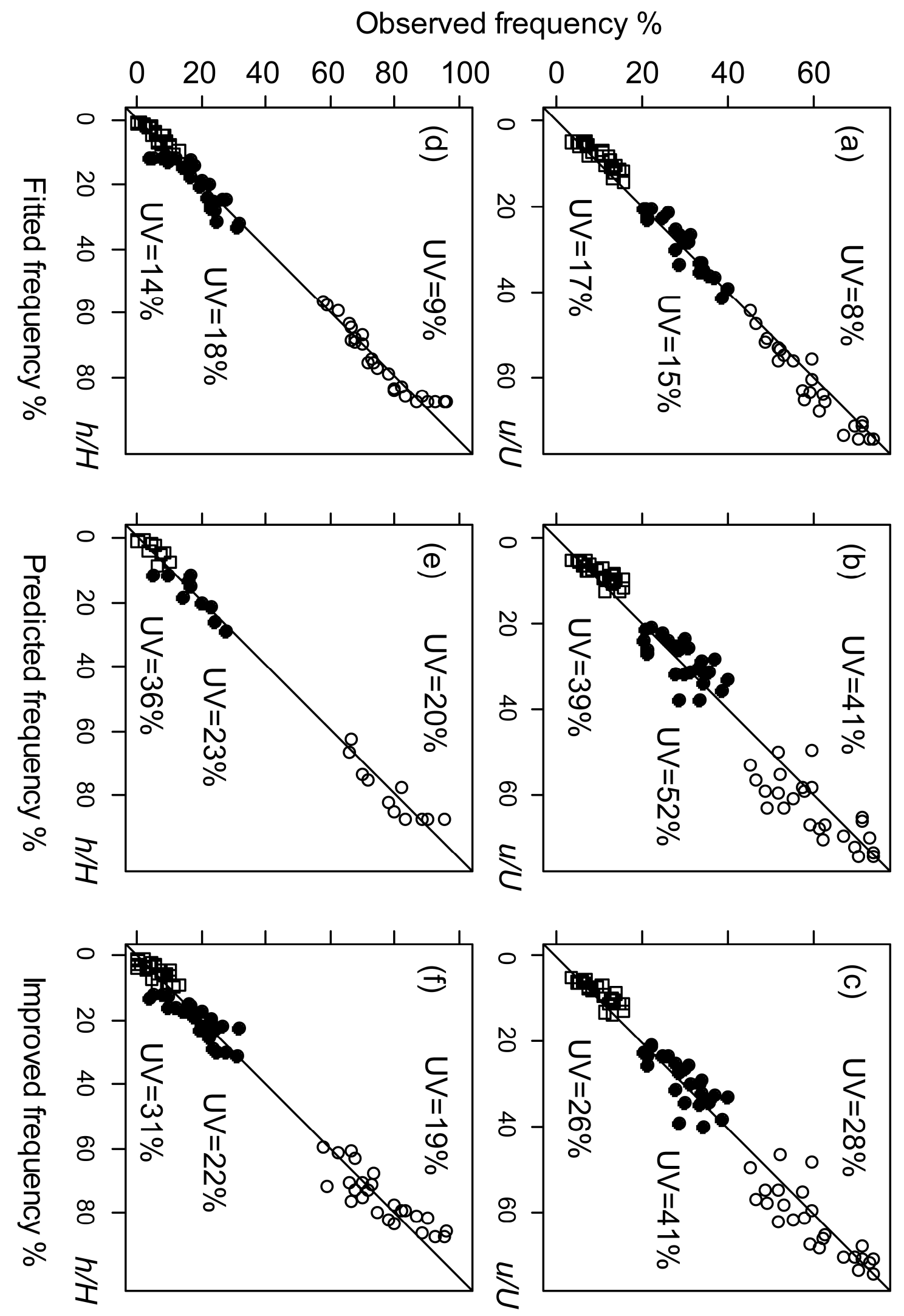

